\title{
Preface: timing and placing regeneration economies
}

Books have multiple origins. They can emerge through conversation, by reflection, by observation, through discussions with publishers and as part of a research project. This book is the result of a combination and juxtaposition of research projects, initiatives and collaborations which led to interdisciplinary discussions about cityregions and regeneration economies.

One of the origins of this book can be traced back to the establishment of the University of Birmingham, UK, in 1900. This new university was intended to support economic and business activity in Birmingham and the West Midlands and to be very much a locally engaged higher education institution. This University still places considerable emphasis on supporting and facilitating inclusive local economic growth. Many projects have been undertaken on the West Midlands that have influenced the shaping of this book. The initial origins of this book are linked to a research project undertaken by John Bryson for Advantage West Midlands (AWM), the then West Midland regional development agency, in 2006. This project aimed to undertake the first integrated analysis of the functioning economic geography of the West Midlands. ${ }^{1}$ Another factor influencing the preliminary discussions was the abolition of AWM and its replacement with a Local Enterprise Partnership (LEP). LEPs were intended to be led by the private sector. In June 2011, the University of Birmingham was requested by the incoming Board of the Greater Birmingham and Solihull Local Enterprise Partnership (GBSLEP) to provide an analysis that would address the following questions:

1. What does a world class city look like?

2. How have successful cities succeeded? What does this mean for Birmingham and the GBSLEP?

3. Is there a model?

These questions were considered to be highly problematic by the University of Birmingham's project team. It would have been possible to produce a brief overview of best practice from other cities and regions, but this would be potentially detri-

\footnotetext{
1 Bryson, J.R. and Taylor, P. (2006), The Functioning Economic Geography of the West Midlands Region, Advantage West Midlands, West Midlands Regional Observatory: Birmingham; Bryson, J.R. and Taylor, M. (2012), 'West Midlands (UK) regional planning (1999-2012), functioning economic geography and the E3I belt: coping with uncomfortable truths', in Robert John Stimson (ed.), Studies in Applied Geography and Spatial Analysis, Edward Elgar Publishing: Cheltenham, UK and Northampton, MA, USA, pp. 196-216.
} 
mental to the development and delivery of an effective local economic development strategy by the GBSLEP.

Conventionally, most local economic development interventions rely on emulating strategies and actions that have been developed in other places. This over-reliance on copying is partly responsible for the ineffectiveness of most policy-led local economic development interventions. In 2007, NESTA published a briefing paper that provided guidance on how to enhance innovation in local economies. ${ }^{2}$ They argued that most local economic policies are 'spatially blind' as they attempt to replicate one region's successes - such as the 'Golden Triangle' bounded by Oxford, Cambridge and London - in every other region, while ignoring specific regional strengths and weaknesses. Emulating strategies and actions that have been developed in other places is a simple approach, but largely ineffective. Instead a best practice manual of what works to enhance city-regional growth with a focus on smarter competitiveness and inclusive economic prosperity was produced. ${ }^{3}$ This analysis was based on the understanding that a best-in-class economic development strategy would focus on enhancing wealth creation, innovation, firm formation and job creation in all sectors that support an area's actual functioning economic geography. This is to argue for a balanced approach that would support the development of diverse and resilient local economies.

The origins of the concept of 'regeneration economies' can be traced back to 2011 and discussions with Geoff Hewings that took place at the University of Birmingham. The timing and the placing of this discussion are important; time and place matter. Geoff is Professor of Geography and Regional Science; Economics; and Urban and Regional Planning at the University of Illinois at Urbana-Champaign and also the Director of the Regional Economics Applications Laboratory (REAL). He is also a graduate of the University of Birmingham. This discussion included a focus on processes of change, evolution and the competitiveness of city-region economies. These discussions led to the concept of 'regeneration economies'. This is Geoff's term to highlight the ongoing processes of change that continue to transform city-regions and especially those regions that are experiencing processes of radical restructuring. This discussion compared the West Midlands region of the UK with the Mid West of the United States and the twin cities of Chicago and Birmingham. At REAL Geoff has developed place-based econometric models of the Mid West and these are used to inform public policy-making and debate, but also to identify and explore interrelationships between different but related place-based processes. One part of these discussions included exploring the creation of a new place-based econometric model of the West Midlands that would be informed by Geoff's MidWest model. The time was appropriate, less than five years after the 2008 economic crisis and economic recession, though the conversation had been ongoing for many

\footnotetext{
2 NESTA (2007), Making innovative places, Policy Briefing Paper MIP/17, NESTA: London.

3 Bryson, J.R., Collinge, C., Love, J., MacNeill, S. and Salder, J. (2011), Smarter Competitiveness and Inclusive Economic Prosperity: Challenges for the Greater Birmingham and Solihull Local Enterprise Partnership, School of Geography, Earth and Environmental Studies, University of Birmingham: Birmingham.
} 
years. The earliest memory of these discussions was a discussion that occurred in Toronto, Ontario, during November 2006.

In 2012, the University of Birmingham established an Institute of Advanced Studies (IAS). This was an important and visionary moment in the development of this University's research culture and institutional structures. We must thank Professor Sir David Eastwood, Vice-Chancellor, University of Birmingham, for initiating and supporting the IAS and also its first director, Professor Malcolm Press. This Institute aims to promote interdisciplinary research by combining expertise from across the breadth of the University of Birmingham to identify and explore major cross-cutting or multi-disciplinary themes that are complex 'wicked problems'. An open competition occurred to identify a thematically focused research project that would be the Institute's launch project. This was an opportunity to develop and shape the conversation with Geoff through a set of co-ordinated research activities. We assembled a multi-disciplinary team to develop a bid that included an external academic steering group consisting of Professor Jennifer Clark, Associate Professor of Public Policy, School of Public Policy, Georgia Institute of Technology (USA), Professor Ian Gordon, Professor of Human Geography, Department of Geography and Environment, The London School of Economics and Political Sciences (UK) and Professor Geoff Hewings. Mr Steve Hollis, then Midlands Chairman KPMG LLP and deputy chairman of Greater Birmingham and Solihull Local and Enterprise Partnership (GBSLEP) agreed to support this initiative by leading a policy stakeholder group that would engage with the project team.

The IAS selected our proposal as one of its inaugural themes and funded the Regeneration Economies: Transforming People, Place and Production project for 18 months (April 2013 to September 2014). The project had three interrelated strands of activity:

1. The development of an integrated or holistic approach to understanding cityregion regeneration economies.

2. An exploration of the consequences of major developments in engineering which would revolutionise production systems transforming the functioning economic geography of regional economies and of the international economy by developing a distinctive research dialogue between engineering and the social sciences.

3. An interrogation of the relationships between firms, regional competitiveness, skills and training drawing upon the premise that the competitiveness of regional economies is increasingly reliant on the availability and quality of skills and human capital as well as the anticipation of future skills and training needs.

Each strand was part of an integrated conceptual framework and each included a multi-disciplinary team. There were three primary activities. First, a series of workshops were held to explore each theme. Second, very focused research projects were identified during the workshop discussions. Third, three long visits to the 
University of Birmingham by academics from the US and China to explore aspects of regeneration economies. These included Professor Nichola Lowe, Associate Professor of City and Regional Planning, University of North Carolina at Chapel Hill and Professor Susan Christopherson, Professor of City and Regional Planning, Cornell. Susan played an important role in shaping the Regeneration Economies project and it is a great sadness that she was unable to participate in writing for this collection. Susan died on 14 December 2016 and it is to Susan that we dedicate this collection.

The Regeneration Economies project was the first step towards the development of an integrated city-region research agenda. The investment by the IAS has led to three subsequent initiatives. First, was the establishment by the University of Birmingham of the City-Region Economic Development Institute (City-REDI) in September 2015 for which John Bryson was the founding director. City-REDI was funded to enhance this university's city-region research with a focus on the development of an integrated or systematic approach to regional economic development and the creation of an integrated place-based econometric model. Both these aims were developed and emerged from the Regeneration Economies project. It is of no surprise that City-REDI's launch included a presentation by Professor Geoff Hewings and that the IAS launch also included a presentation by Professor Hewings - albeit different presentations. Second, in May 2016 a project team led by Bryson was awarded a research grant from the Urban Living Partnership. This was the first programme funded by all UK research councils (RC-UK) with Innovate UK and the projects were intended to develop an integrated approach to the challenges facing British cities. The Urban Living Birmingham project, like City-REDI, had its origins in the IAS funded Regeneration Economies project. Third, in August 2017, a project team led by Professor Francis Pope and with Dr Lauren Andres and Professor John Bryson was awarded a grant to develop A Systems Approach to Air Pollution in East Africa (ASAP-East Africa). The ASAP project commenced in September 2017 and is developing a new and interdisciplinary research framework for deconstructing and creating a more liveable and sustainable urbanisation that works for all. This project contains what can be termed the Regeneration Economies project's hallmark, or distinguishing feature. This is a concern with the development of an integrated approach to city-regions. This integrated and interdisciplinary approach tries to break down, challenge and overcome both academic disciplinary boundaries and policy silos. It is worth noting that through this project we are also expanding the geographical boundaries of our systemic framework by aiming to apply it to the so-called Global South.

The place and time of the ideas that led to this book reflect a set of place-based interactions between academics and policy-makers who have come together to explore city-region economies. It also reflects the strength, diversity and international scope of urban-related interdisciplinary research at the University of Birmingham. There are perhaps two lessons that come from the origins of this collection. First, there is the importance of measuring the impacts of any intervention over a very long time frame. Thus, the IAS funding of Regeneration Economies 
should be considered as a long-term investment whose impacts are still developing and emerging and will perhaps continue to emerge over the next decade. Second, multi-disciplinary research is both difficult and extremely important. It is difficult as barriers exist that are hard-wired and act to prevent or discourage multidisciplinary research. These barriers include, in the UK, the single disciplinary focused Research Excellence Framework (REF) and more widely the disciplinary focus of many academic journals, editors and reviewers. It is critical that academics and universities work against these barriers as the problems facing the Earth and its inhabitants are increasingly multi-disciplinary and far too complex to be explored through a single disciplinary lens. This book seeks to contribute to the research debate on city-regions and to encourage the development of multi-disciplinary and more integrated approaches.

John R. Bryson and Lauren Andres

December 2017 